\title{
Requirement for an intact cytoskeleton for volume regulation in boar spermatozoa
}

\author{
A M Petrunkina, M Hebel, D Waberski, K F Weitze and E Töpfer-Petersen \\ Institute for Reproductive Medicine, School of Veterinary Medicine Hanover, Bünteweg 15, 30559 Hanover, \\ Germany \\ Correspondence should be addressed to A M Petrunkina; Email: Anna.Petrounkina@tiho-hannover.de
}

\begin{abstract}
Osmotically induced cell swelling triggers a chain of events leading to a net loss of major cell ions and water, resulting in cell volume recovery, a process known as regulatory volume decrease (RVD). In many cell types, there is an evidence that the cytoskeleton may play a role in the initial sensing and transduction of the signal of volume change. In this study, we tested the hypothesis that an intact microfilament and microtubule network is required for volume response and RVD in boar sperm before and after capacitation treatment and whether addition of cytochalasin $D$ and colchicine to the capacitation medium would affect volumetric behaviour. Capacitation is a series of cellular and molecular alterations that enable the spermatozoon to fertilize an oocyte. Cell volume measurements of washed sperm suspensions were performed electronically in Hepes-buffered saline solutions of 300 and $180 \mathrm{mosmol} / \mathrm{kg}$. After exposure to hypoosmotic conditions, boar sperm showed initial swelling (up to $150 \%$ of initial volume within $5 \mathrm{~min}$ ), which was subsequently partially reversed (to about $120-130 \%$ after $20 \mathrm{~min})$. Treatment with cytochalasin D led to reduced initial swelling $(1 \mu \mathrm{mol} / \mathrm{l})$ and loss of RVD in washed sperm $(1-10 \mu \mathrm{mol} / \mathrm{l})$ and at the beginning of incubation under capacitating conditions $(5 \mu \mathrm{mol} / \mathrm{l})$. Short treatment with $500 \mu \mathrm{mol} / \mathrm{I}$ colchicine affected the volume regulatory ability in sperm under capacitating conditions but not in washed sperm. No significant differences in cell volume response were observed after subsequent addition of cytochalasin $D$ and colchicine to the suspensions of sperm incubated for $3 \mathrm{~h}$ under capacitating conditions. However, the incubation under capacitating conditions in the presence of cytochalasin D led to improved volume regulation at the end of the incubation period $(23 \%)$. The microfilament network appears to be important for volume regulation in washed boar spermatozoa while intact microtubules do not seem to be necessary for osmotically induced RVD. The changes in cytoskeleton microfilament organization during capacitation, possibly affecting the osmotically induced volume response, appear to occur at the later stages of capacitation, whereas changes in microtubules, related to volume regulatory ability, may be programmed within the first stages of capacitation.

Reproduction (2004) 127 105-115
\end{abstract}

\section{Introduction}

Cell volume is essentially determined by the intracellular content of osmotically active solute relative to the osmolarity of the extracellular fluid. Sperm cells are known to behave as perfect osmometers (Drevius 1972), i.e. their initial response to anisotonic conditions is proportional to the changes in osmolality, thus they swell in response to hypotonic conditions. In spermatozoa of most mammals, osmotic cell swelling triggers a chain of events leading to a net loss of the major cell ions $\mathrm{Cl}^{-}, \mathrm{K}^{+}$, organic osmolytes and osmotically obliged water (Kulkarni et al. 1997, Petrunkina et al. 2001). This loss results in cell volume recovery in almost all mammalian cells, a process known as regulatory volume decrease (RVD) (Hoffmann \& Dunham 1995). Thus volume regulation essentially involves the activation of processes for transferring osmolytes into or out of the cell, so as to re-establish osmotic equilibrium (see reviews by Grinstein et al. 1984, Sarkadi \& Parker 1991, Al-Habori 1994, O'Neill 1999). Relatively little is known regarding the details of the regulatory mechanisms present in sperm. Kulkarni et al. (1997) reported the presence of non-selective pores in bull spermatozoa through which $\mathrm{K}^{+}$was released in response to hypotonic challenge. By blocking these channels with quinine, it has been shown that they play a major role in mediating the swelling response in bull, boar and human sperm (Kulkarni et al. 1997, Petrunkina et al. 2001, Yeung \& Cooper 2001). Recently, Yeung et al. (1999) were able to induce swelling-associated changes by treatment with inhibitors of anion channels as well as $\mathrm{K}^{+}$channels in mouse spermatozoa exposed to hypotonic conditions. 
The early events triggered by swelling of mammalian spermatozoa resulting in activation of ion transport pathways are still poorly understood. Several lines of evidence suggest that the cytoskeleton may play a role in the initial sensing and transduction of the signal of volume change in many cell types. In tumour cells, the hypotonically induced changes were linked to the changes in the microfilament network (Cornet et al. 1993), and the disruption of the microfilaments by cytochalasin B resulted in inhibition of volume regulation. Similarly, disruption of the cytoskeleton by cytochalasin D led to changes in the cell volume of Xenopus oocytes similar to that resulting from hypotonic stress (Ahmed et al. 2000). In the presence of colchicine, a microtubule-disrupting agent, RVD in leukocytes was totally inhibited, which corresponded to loss of microtubules. Similarly, volume regulation was inhibited in Jurkat cells incubated with the actin-binding agents cytochalasin B or D (Downey et al. 1995). Not only may the structural integrity of the cytoskeleton as a mechanical basis for cell volume response be crucial for the appropriate volume regulation, but the mechanisms involved in the volume regulation, such as ionic conductances, may be directly affected by disruption of microfilaments or microtubules. Major ions involved in RVD (i.e. $\mathrm{K}^{+}$and $\mathrm{Cl}^{-}$) should leave the cell in parallel in order to maintain the electroneutrality. Inhibition or activation of $\mathrm{Cl}^{-}$channels would result in modified volume regulation. Addition of microfilament/microtubule stabilizing or disrupting compounds was shown to affect $\mathrm{Cl}^{-}$conductance in some cell types (Strange et al. 1996). Taxol, a microtubule-stabilizing compound, inhibited the activation of volume-sensitive $\mathrm{Cl}^{-}$channels and volume regulation in a dose-dependent manner (Shen et al. 1999). Koch \& Korbmacher (2000) detected a reduced volume response after addition of cytochalasin D. Furthermore, these investigators observed similar voltage changes to those under hyperosmolar conditions, and found that the non-selective cation channel (affected by cytochalasin D) may be involved in this cell volume response.

Although the involvement of the structural elements of the cytoskeleton in volume regulation has been demonstrated in a variety of other cell types, the relationship between an intact cytoskeleton and volume response in sperm cells has only recently come under investigation. Particularly, cytochalasin D has been shown to influence hypoosmotic swelling in mouse and dog spermatozoa and, temperature-dependently, the isoosmotic volume in dog spermatozoa (Noiles et al. 1997, Petrunkina et al. 2004). However, there is a lack of studies revealing the relationship with RVD. This relationship is especially interesting, and not yet investigated is the aspect of sperm capacitation as the cytoskeleton undergoes changes during the capacitation process (for review see Yanagimachi 1994, De Lamirande et al. 1997). Capacitation is a series of cellular and molecular alterations that enable the spermatozoon to fertilize an oocyte. Sperm cell volume response seems also to be modified during capacitation (Petrunkina \& Töpfer-Petersen 2000, Petrounkina et al. 2000), and the capacitation-linked changes in the cytoskeleton may be connected to these volume changes. In this study, we tested the hypothesis that an intact microfilament and microtubule network is required for appropriate osmotically induced volume response and RVD in boar sperm before and after capacitation treatment. Furthermore, we tested whether the addition of cytochalasin D, an actin-depolymerizing compound, and colchicine, a microtubule-disrupting agent, to the capacitation medium would affect volumetric behaviour.

\section{Materials and Methods}

In essence, our experimental approach consisted of diluting washed sperm samples into isotonic $(300 \mathrm{mOsm} / \mathrm{kg})$ or hypotonic $(180 \mathrm{mOsm} / \mathrm{kg})$ medium at $39^{\circ} \mathrm{C}$, and taking sub-samples at timed intervals thereafter for analysis of the population volume distribution. Effects were largely judged by comparing the modal volumes of such distributions. Much of the methodology used was based on earlier studies of sperm volumetric behaviour (Petrunkina et al. 2000, 2001), which may be consulted for further details and approach explanation.

\section{Chemicals}

Unless otherwise stated, chemicals were obtained from Merck AG, Darmstadt, Germany and Sigma AG (Sigma-Aldrich), Steinheim, Germany.

\section{Basal experimental medium}

Two variants of a standard Hepes-buffered saline medium (HBSM) (Harrison et al. 1993) were used as vehicles for experimentation. Isotonic HBSM (isoHBSM; $300 \mathrm{mOsm} / \mathrm{kg}$ ) consisted of $137 \mathrm{mmol} / \mathrm{l} \mathrm{NaCl}, 10 \mathrm{mmol} / \mathrm{l}$ glucose, $2.5 \mathrm{mmol} / / \mathrm{KOH}$ and $20 \mathrm{mmol} / \mathrm{l}$ Hepes buffered with $\mathrm{NaOH}$ to $\mathrm{pH} 7.4$ at $39^{\circ} \mathrm{C}$. Hypotonic HBSM (hypoHBSM; $180 \mathrm{mOsm} / \mathrm{kg}$ ) was prepared by diluting isoHBSM with water to the correct osmolality. To minimize detection of particulate 'noise' during cell volume measurements, the media were passed through a $0.2 \mu \mathrm{m}$ filter before use (Minisart, Sartorius, Göttingen, Germany).

\section{Semen processing}

Boar semen ('sperm-rich fraction') was obtained from four fertile animals, from the Institute of Reproductive Medicine's boar colony. The samples were collected (generally twice a week) by the 'gloved hand' method via sterile gauze (to remove gel). Immediately after collection the semen was transferred to the laboratory and diluted in Beltsville TS extender (Johnson et al. 1988) to a concentration of $0.8-1.0 \times 10^{8}$ cells $/ \mathrm{ml}$. Aliquots $(3 \mathrm{ml})$ were then washed through a Percoll gradient (Harrrison et al. 1993), after which the sperm pellet was resuspended in residual $70 \%$ Percoll to a final concentration of about $2-3 \times 10^{8}$ cells $/ \mathrm{ml}$. 
Prior to incubation, semen samples were maintained at a minimum of $25^{\circ} \mathrm{C}$ in order to avoid cold shock. Processed samples were used for experimental studies within $1 \mathrm{~h}$ of collection.

\section{Sperm quality estimations}

Sperm morphology was examined in samples taken from the native ejaculates shortly after semen collection, and estimations were made of motility and of acrosomal integrity at the start of each experiment. The methodology used for these assessments was as described by Petrounkina et al. (2000) and references therein. Membrane integrity status was checked during the experimental incubations using propidium iodide staining (Harrison \& Vickers 1990). The boar samples were routinely assessed in wet mounts after $5 \mathrm{~min}$ of incubation in both iso- and hypotonic conditions with and without additives.

\section{Experiment 1: investigation of effects of cytochalasin $D$ and colchicine on boar sperm}

Aliquots of washed sperm suspensions were pre-incubated in isoHBSM in the presence of various concentrations of cytochalasin D $(1-15 \mu \mathrm{mol} / \mathrm{l})$ and colchicine (0.5$5 \mathrm{mmol} / \mathrm{l}$ ); sperm concentration during this pre-incubation was about $1-2 \times 10^{7} \mathrm{cells} / \mathrm{ml}$. Control samples were similarly incubated in isoHBSM without additives.

After the $10 \mathrm{~min}$ pre-incubation, samples from each suspension were transferred to HBSM media each containing the same additive as the parent pre-incubation medium (final sperm concentration about $1-3 \times 10^{5}$ cells $/ \mathrm{ml}$ ) and incubated as described above. The isotonic sperm suspension was sampled for cell volume measurement after $5 \mathrm{~min}$ (isoosmotic volume distributions remained essentially constant during 20 min incubation in isoHBSM at $39^{\circ} \mathrm{C}$, cf. Petrunkina et al. (2001)), while the hypotonic suspension was sampled after 5 and $20 \mathrm{~min}$.

In the experiments involving colchicine and cytochala$\sin \mathrm{D}$, where an additive was added from a stock solution prepared in alcohol or DMSO, the final concentration of solvent in the testing solution was less than $0.5 \%(\mathrm{v} / \mathrm{v})$.

\section{Experiment 2: investigation of effects of cytochalasin $D$ and colchicine on capacitated sperm}

For capacitation treatment of boar spermatozoa, a complete Tyrode's bicarbonate medium, (Tyrode medium) (Harrison et al. 1993) was used, consisting of $96 \mathrm{mmol} / \mathrm{l} \mathrm{NaCl}$, $3.1 \mathrm{mmol} / \mathrm{l} \mathrm{KCl}, 5 \mathrm{mmol} / \mathrm{l}$ glucose, $0.4 \mathrm{mmol} / \mathrm{l} \mathrm{MgSO}_{4}$, $15 \mathrm{mmol} / \mathrm{l} \quad \mathrm{NaHCO}_{3}, 2 \mathrm{mmol} / \mathrm{l} \quad \mathrm{CaCl}_{2}, \quad 0.3 \mathrm{mmol} / \mathrm{l}$ $\mathrm{NaH}_{2} \mathrm{PO}_{4}, 1 \mathrm{mmol} / \mathrm{l}$ Na-pyruvate, $21.6 \mathrm{mmol} / \mathrm{l}$ Na-lactate, $3 \mathrm{mg} / \mathrm{ml} \mathrm{BSA}$ and $20 \mathrm{mmol} / \mathrm{l}$ Hepes of $\mathrm{pH} 7.4(\mathrm{pH} \mathrm{7.4}$, $290 \mathrm{mOsm} / \mathrm{kg}$ ). Before use, it was equilibrated at $39^{\circ} \mathrm{C}$ for $1 \mathrm{~h}$ in a humidified atmosphere containing $5 \% \mathrm{CO}_{2}(\mathrm{pH}$ $7.4,300 \mathrm{mOsm} / \mathrm{kg}$ ). After preparation, the medium were passed through a $0.2 \mu \mathrm{m}$ single-use filter unit.

Sperm samples ( $n=4$ ejaculates) were incubated in Tyrode medium at a concentration of about $1 \times 10^{8}$ spermatozoa $/ \mathrm{ml}$. At 5 and $170 \mathrm{~min}$ of incubation, cytochalasin D $(5 \mu \mathrm{mol} / \mathrm{l})$ or colchicine $(500 \mu \mathrm{mol} / \mathrm{l})$ was added to the incubated cell suspensions. As a control, incubated sperm suspensions without additive were used. After $10 \mathrm{~min}$ subsequent incubation, the sub-samples of treated and non-treated sperm suspensions were taken and transferred to the isotonic or hypotonic HBSM testing solutions (final sperm concentration about $1-3 \times 10^{5}$ cells $/ \mathrm{ml})$, incubated in the presence or absence of cytochalasin D and colchicine as described above for Percollwashed sperm, and the volumetric measurements performed after 5 and $15 \mathrm{~min}$ of incubation in isotonic and hypotonic solutions respectively.

\section{Experiment 3: effects of cytochalasin $D$ and colchicine on capacitation-induced changes}

Sperm samples ( $n=4$ ejaculates) were incubated in the capacitation medium (described above) including $5 \mu \mathrm{mol} / \mathrm{l}$ cytochalasin D or $500 \mu \mathrm{mol} / /$ colchicine. As a control, a capacitation medium without additive was used. After $180 \mathrm{~min}$ of incubation, the sub-samples of sperm were taken and transferred to isoHBSM or hypo HBSM, incubated in the presence or absence of cytochalasin D/colchicine as described above, and the volumetric measurements performed.

Additionally, motility measurements on sperm incubated in the presence or absence of cytoskeleton modulators were performed at 0, 60, 120 and $180 \mathrm{~min}$. Cell viability was estimated at 0,60, 120 and $180 \mathrm{~min}$ of incubation. The capacitation rate of sperm was indirectly tested by inducing the acrosome reaction with lysophosphatidylcholine (LPC); $10 \mu \mathrm{l}$ of LPC stock solution (consisted of $100 \mathrm{mg}$ LPC in $1 \mathrm{ml}$ chloroform/methanol solution diluted with HBSM 1:100) were added to $1 \mathrm{ml}$ of sperm suspension incubated in Tyrode medium and incubated for $5 \mathrm{~min}$ prior to testing by indirect immnofluorescence. Tyrode-incubated sperm suspensions were $5 \mathrm{~min}$ pre-incubated with fluorescein isothiocyanate-labelled phytohaemagglutinin $(5 \mu \mathrm{g} / \mathrm{ml})$ allowing quantification of the spontaneous and induced acrosome reaction.

\section{Motility changes}

Semen samples were used to characterize motility changes of boar spermatozoa during incubation under capacitating conditions and to relate these changes to other parameters.

The motility measurements were performed using a computer-assisted motility analysis system (Minitüb, Tiefenbach, Germany). Samples were taken at each sampling point as described above and $8 \mu \mathrm{l}$ of sperm were placed in a cell chamber (MTM Mika Chamber; Minitüb) under a microscope. The tracks of at least 200 sperm were recorded and evaluated. On average, four images were evaluated in 32 frames per analysis at 20 ms intervals. Cell Motion Analyser 2.0 Software (Medical Technologies, Montreux, Switzerland) was used for evaluation. The 
percentage of motile sperm and VAP, VSL, VCL (average path velocity, straightline velocity and curvilinear velocity respectively) were evaluated.

\section{Cell volume measurements}

At each sampling time-point, a single sample from each incubated sperm suspension was passed through a CASY 1 cell counter (Schaerfe Systems $\mathrm{GmbH}$, Reutlingen, Germany), which produced cell volume information on the basis of cell frequency distribution. During the measurements, the cells suspended in the electrolyte solution pass through the capillary pore. The changes in the electric resistance caused by cells passing through the pore lead to voltage changes and are proportional to the cell volume. The measurement signal is registered with the frequency of $1 \mathrm{MHz}$. From the single signal measurements the entire signal course is calculated by integration (pulse area analysis). This methodology allows high accuracy and resolution of measurements (dynamics $>1: 32000$ in volumes); the pulse area values are not dependent on orientation of the sperm cells in the capillary pore or on the geometrical shape. The recorded electric signals are converted to volume values using a channel analyser with 512000 measured volume channels (each channel contains the cells which produces the signal with corresponding pulse area by passing the pore). Further, these original volume signals are re-calculated to a linear distribution within 1024 effective cell size channels. The sample volume setting was $200 \mu \mathrm{l}$ and the size scale $10 \mu \mathrm{m}$; each sampling obtained data from more than 12000 cells.

Data are presented in volume equivalents in $\mathrm{fl}$ (femtolitres; $\left.\mu \mathrm{m}^{3}\right)$. To obtain real cell volumes, the volume equivalents should be multiplied by a correction factor assessed using latex beads. The modal values of the latex bead distribution measured with the cell counter were compared with the value provided by the manufacturer $(3.4 \mu \mathrm{m})$ and the correction factor was determined $(F=1.37)$. Because the electrical conductivity of hypoHBSM was lower than that of isoHBSM (different concentrations of electrolyte), a correction factor (1.10) was applied to data recorded from sperm suspensions in the former medium. This correction factor was obtained according to Petrounkina et al. (2000).

\section{Analysis of volumetric data}

Unless otherwise stated, the analyses used the modal volumes (corrected for the different osmotic conditions); these values were obtained directly from the cell volume measurements using the CASY software. (Modal volume has been shown to be a more sensitive parameter of volume change than mean volume - see Petrunkina \& Töpfer-Petersen (2000).)

The relative volume shift $V_{\mathrm{r}}$ was used as a measure of the volume regulation in response to anisotonic conditions. It was defined as $V_{\mathrm{r}}=V_{\text {hypo }} / V_{\text {iso, }}$ where $V_{\text {hypo }}$ was the modal value of the hypotonic volume distribution and
$V_{\text {iso }}$ was the modal value of the isotonic volume distribution. In the situation that several sperm subpopulations contributed to a distribution, the values pertaining to the largest osmotically active subpopulation were used. A cell subpopulation was considered as osmotically active if its $V_{\mathrm{r}}$ was greater than 1 .

Unless otherwise stated, values presented are mean values. Differences were considered to be significant if the calculated probability was less than $5 \%(P<0.05)$. The observed effects of cytochalasin D/colchicine were verified by ANOVA (SAS Software: General Linear Model).

\section{Results}

\section{Conventional parameters}

As judged by conventional spermatological parameters, the native ejaculates of the boars involved in the study were in the normal range: motility was in the range $70-90 \%$, morphological abnormalities were less than $30 \%$ and membrane integrity was more than $80 \%$.

\section{Role of microfilaments in volume response of boar spermatozoa}

\section{Effect of cytochalasin D on cell volume response and viability of washed boar spermatozoa}

In freshly diluted, Percoll-washed boar spermatozoa, significant effects of cytochalasin D on volume response were observed. Incubation of spermatozoa with 1, 2 and $5 \mu \mathrm{mol} / \mathrm{l}$ cytochalasin D led to a decreased volume after $5 \mathrm{~min}$ of exposure to hypotonic conditions $(P<0.05$ for $1 \mu \mathrm{mol} / \mathrm{l}$; Fig. 1). A gradual increase in the hypotonic volume was observed between concentrations 1 and $15 \mu \mathrm{mol} / \mathrm{l}$ so that volumes at higher cytochalasin D concentrations did not differ from controls. The relative volume response after $5 \mathrm{~min}$ of exposure to hypotonic conditions was similarly reduced. Cell volumes of cytochalasin D-treated boar sperm after 20 min of exposure to hypotonic conditions were somewhat increased as compared with $5 \mathrm{~min}$ of exposure, while in controls the cell volume decreased from 5 to $20 \mathrm{~min}$ of incubation. No noticeable RVD was observed at all concentrations at which the levels of viability were maintained $(21 \%$ of volume decrease observed in controls). Incubation of cell suspensions with cytochalasin $\mathrm{D}$ resulted in slowly rising proportions of membrane-defect cells (Fig. 2). At a concentration of $15 \mu \mathrm{mol} / \mathrm{l}$ the percentage of membranedefect cells in cytochalasin D-treated suspensions was significantly increased. The isotonic volume of freshly diluted, Percoll-washed boar spermatozoa was not significantly affected by cytochalasin D.

\section{Effect of cytochalasin D on volume response and membrane integrity of capacitated boar spermatozoa}

At the beginning of incubation under capacitating conditions, cytochalasin $\mathrm{D}$ produced a similar effect on the volume response of boar spermatozoa as for washed 


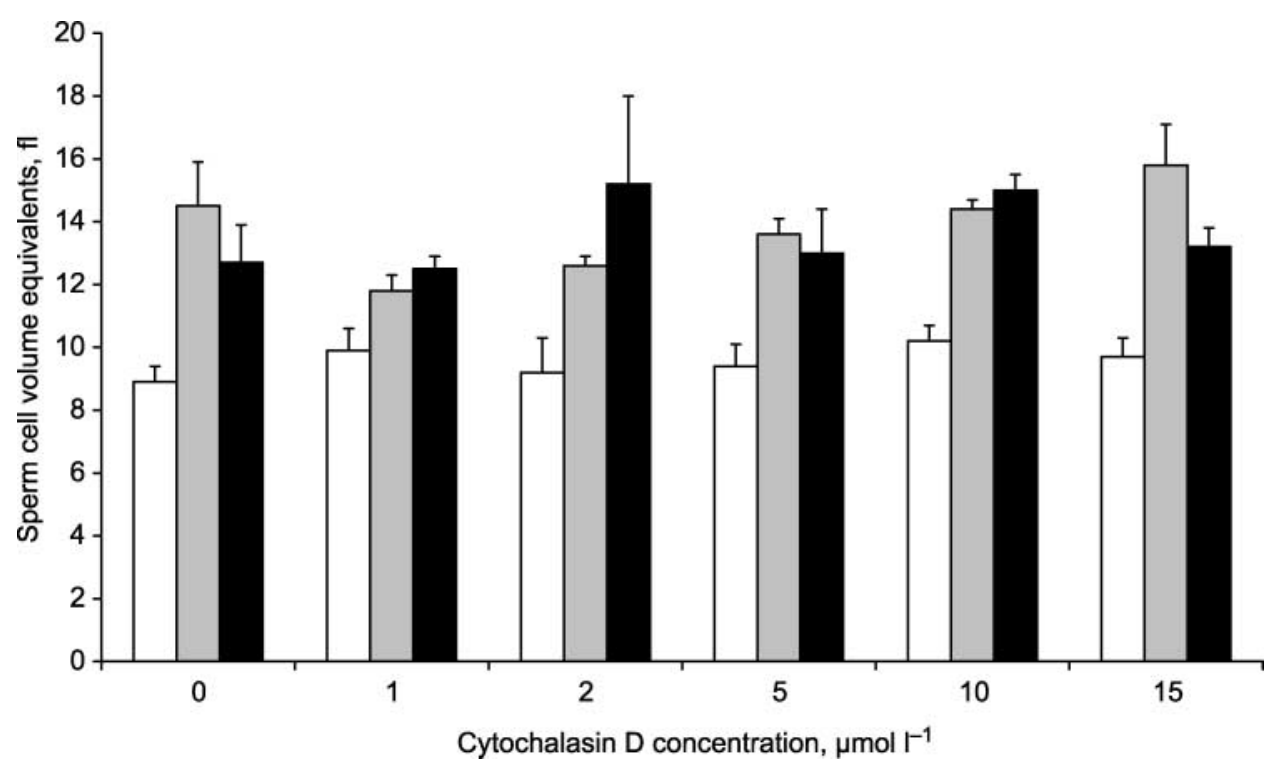

Figure 1 Sperm cell volume response to cytochalasin D. White bars: isotonic cell volume; grey bars: hypotonic cell volume after $5 \mathrm{~min}$ of exposure to hypotonic conditions; black bars: hypotonic cell volume after 20 min of exposure to hypotonic conditions. Concentrations from 1 to $15 \mu \mathrm{mol} / / \mathrm{l}$ were tested. Control sperm showed RVD, cytochalasin D-treated sperm showed no RVD at concentrations where viability was not affected $(<15 \mu \mathrm{mol} / \mathrm{l}) . n=3-4$; data presented as means \pm S.E.M.

sperm. Cell volume after $5 \mathrm{~min}$ of exposure to hypotonic conditions was significantly reduced as compared with controls (13.5 to $15.7 \mathrm{fl}$; Fig. 3). $V_{\mathrm{r}}$ after $5 \mathrm{~min}$ was similarly significantly diminished $(P<0.05)$. The cell volume after $15 \mathrm{~min}$ exposure to hypotonic conditions was elevated as compared with $5 \mathrm{~min}$, similarly to washed sperm treated with lower cytochalasin D concentration (Figs. 1 and 3). No RVD was observed at the beginning of incubation under capacitating conditions $(P<0.08$ as compared with controls). At the end of capacitation treatment, no significant differences between control and cytochalasin D-treated suspensions were observed (Fig. 3).

Although cell death progressed during capacitation treatment (from 20 to $44 \%$ at the end of incubation, $P<0.05)$, no significant differences were found between proportions of membrane-defect cells in capacitated sperm suspensions subsequently incubated in the presence of

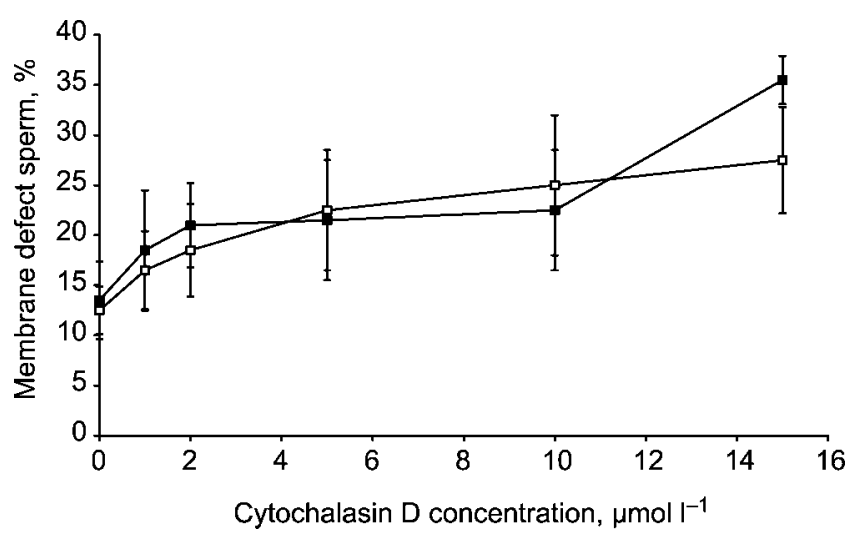

Figure 2 Sperm viability in the presence of cytochalasin D. $\square$, proportion of PI-positive sperm under isotonic conditions; $\mathbf{\square}$, proportion of PI-positive sperm under hypotonic conditions. At a concentration of $15 \mu \mathrm{mol} / /$ the cell death is significantly increased under both osmotic conditions. $\mathrm{PI}=$ propidium iodide. $n=3-4$; data presented as means \pm S.E.M. cytochalasin $\mathrm{D}$ and in sampling solutions without additive $(P>0.05$, data not shown).

\section{Cytoskeletal requirements for capacitation-induced changes in volume response, membrane integrity, acrosomal state and motility}

In this series, incubation-induced parameter changes in sperm incubated in Tyrode medium in the presence of cytochalasin $\mathrm{D}$ were compared with those of sperm incubated

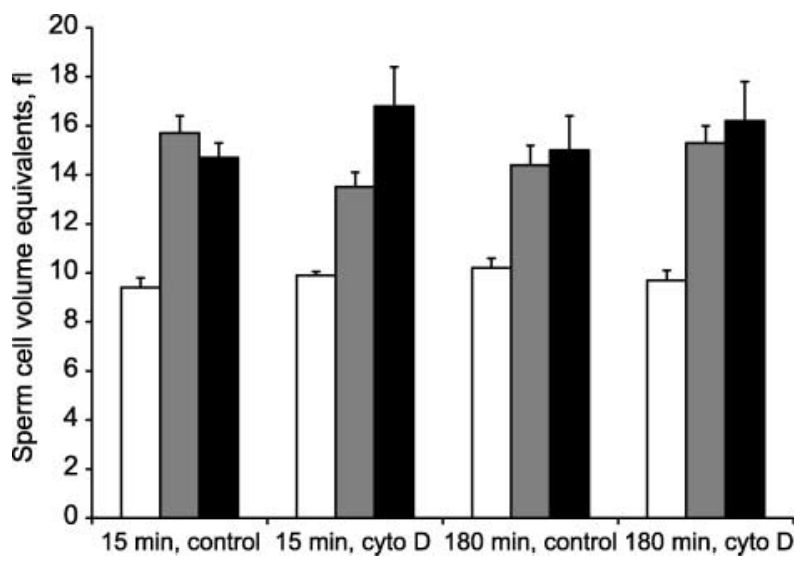

Figure 3 Cell volume response to cytochalasin $\mathrm{D}$ at the beginning and at the end of capacitation treatment. White bars: isotonic cell volume; grey bars: hypotonic cell volume after $5 \mathrm{~min}$ of exposure to hypotonic conditions; black bars: hypotonic cell volume after $20 \mathrm{~min}$ of exposure to hypotonic conditions. Volumetric measurements were made on sperm incubated in the presence of cytochalasin D in the incubation and testing solutions and control sperm after 15 and $180 \mathrm{~min}$ of incubation. A concentration of $5 \mu \mathrm{mol} / \mathrm{l}$ was tested. Cytochalasin D-treated sperm showed a reduced hypotonic volume after $5 \mathrm{~min}$ exposure to hypotonic conditions at the beginning of incubation; and further volume increase instead of RVD at both the beginning and end of the incubation period. $n=4$; data presented as means \pm S.E.M. 


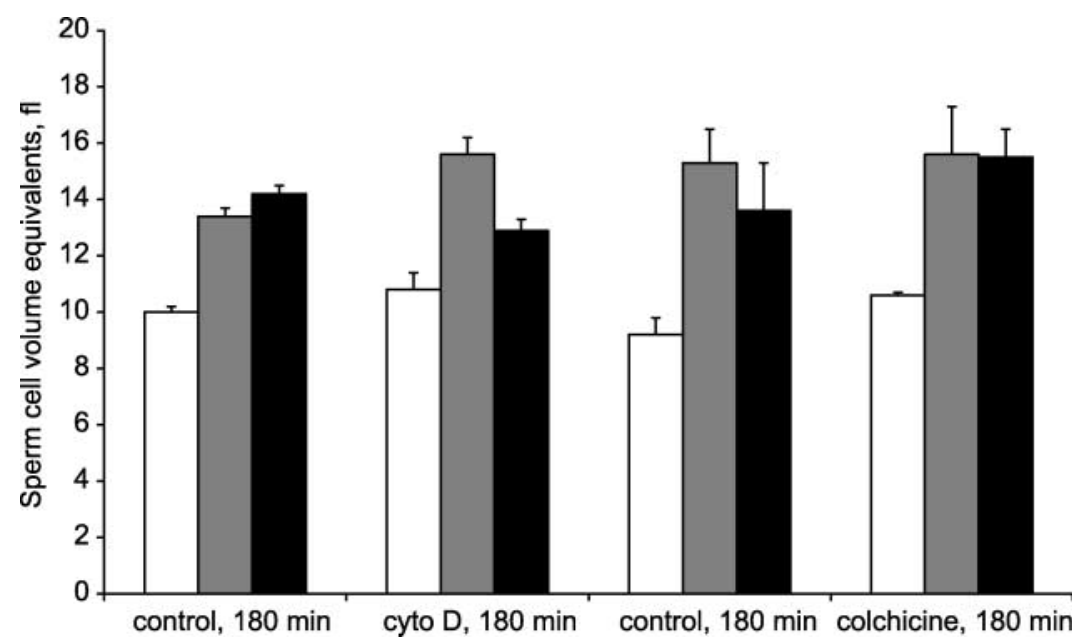

Figure 4 Cell volume response of sperm incubated for $3 \mathrm{~h}$ in capacitation medium in the presence and absence of cytochalasin $\mathrm{D}$ or colchicine. White bars: isotonic cell volume; grey bars: hypotonic cell volume after $5 \mathrm{~min}$ of exposure to hypotonic conditions; black bars: hypotonic cell volume after $20 \mathrm{~min}$ of exposure to hypotonic conditions. Sperm incubated with cytochalasin D showed a tendency to improved RVD as compared with controls. Colchicine-treated sperm had increased values for the isotonic volume. $n=4$; data presented as means \pm S.E.M.

without additives to test whether the modification of the cytoskeletal sperm organization during capacitation may account for associated changes in sperm cell volume such as complete loss of RVD in non-treated capacitated sperm.

At the end of incubation in the presence of cytochalasin $D$, significantly higher hypotonic volumes after $5 \mathrm{~min}$ $(15.6 \mathrm{vs} 13.4 \mathrm{fl}$ in controls, $P<0.05)$ and noticeably lower hypotonic volumes after $15 \mathrm{~min}(12.9 \mathrm{vs} 14.2 \mathrm{fl}$ in controls, $P<0.06$ ) than in controls were observed (Fig. 4). Unlike controls, sperm incubated with cytochalasin D were able to regulate their volume after $180 \mathrm{~min}$ under capacitating conditions $(P<0.05)$. No effects on total motility, VSL, VAP and VCL in the population of motile cells were observed between cells capacitated in the presence of cytochalasin D and without it (data not shown). Although addition of cytochalasin $\mathrm{D}$ resulted in a significantly higher proportion of membrane-defect cells at the beginning of incubation $(P<0.05)$ and the levels remained higher during incubation in capacitating medium, the rates of cell death were either equal (isotonic conditions) or the rate of cell death in the presence of cytochalasin D was even lower than without it (hypotonic solution, Fig. 5). Both at the beginning and at the end of incubation the rate of spontaneous acrosome reaction was higher in the presence of cytochalasin D (10.8 vs $5.8 \%$ at the beginning and 14.8 vs $11 \%$ at the end), while the rate of induced acrosome reaction was lower (14.5 vs $16.3 \%$ at the beginning and 19.3 vs $22 \%$ at the end), although it was not statistically significant.

\section{Role of microtubules in boar sperm volume response}

Effect of colchicine on sperm cell volume response and viability

Incubation of spermatozoa with $500 \mu \mathrm{mol} / \mathrm{l}$ colchicine resulted in increased cell volume after $5 \mathrm{~min}$ of exposure to hypotonic conditions (Fig. 6). Cell volume after $20 \mathrm{~min}$ of exposure to hypotonic conditions was higher than in controls at all concentrations (this tendency was not significant). The ability to regulate cell volume was abolished at concentrations higher than $500 \mu \mathrm{mol} / \mathrm{l}$. However, the proportion of membrane-defect cells increased rapidly in a concentration-dependent manner (Fig. 7). Only at a concentration of $500 \mu \mathrm{mol} / \mathrm{l}$ (where the

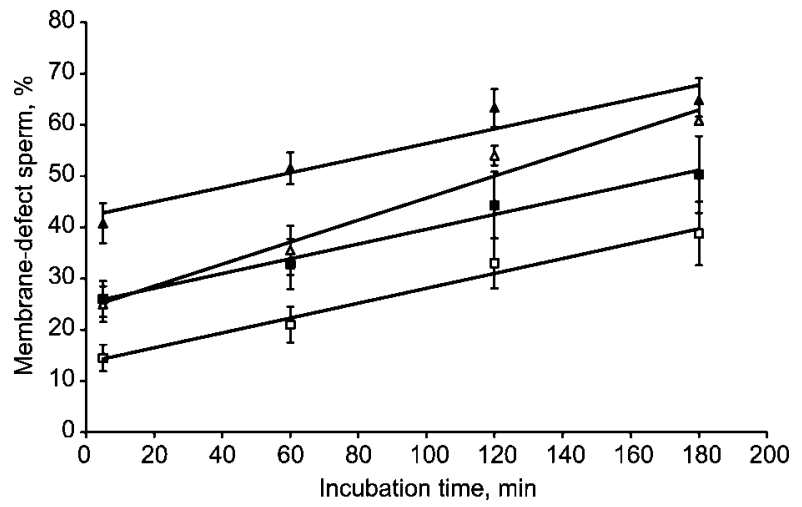

Figure 5 Sperm viability during incubation under capacitating conditions in the presence and absence of cytochalasin D. $\square$, the percentage of membrane-defect sperm in control suspensions assessed under isotonic conditions; $\Delta$, the percentage of membrane-defect sperm in control suspensions assessed under hypotonic conditions;

$\mathbf{\square}$, the percentage of membrane-defect sperm in suspensions incubated with cytochalasin D assessed under isotonic conditions; $\boldsymbol{\Lambda}$, the percentage of membrane-defect sperm in suspension incubated with cytochalasin D assessed under hypotonic conditions. Under both isoand hypotonic conditions the cell death is slightly elevated but progressed at almost the same (iso-) or slightly slower (hypotonic conditions) rate. Cytochalasin $\mathrm{D}$, isotonic conditions: $\mathrm{PI}=0.14 \mathrm{t}+25.18$; $R^{2}=0.99$; controls, isotonic conditions: $\mathrm{PI}=0.14 \mathrm{t}+13.58$; $R^{2}=0.98$; cytochalasin $\mathrm{D}$, hypotonic conditions:

$\mathrm{PI}=0.14 \mathrm{t}+42.08 ; R^{2}=0.92 ;$ controls, hypotonic conditions: $\mathrm{PI}=0.21 \mathrm{t}+24.19 ; R^{2}=0.97 . \mathrm{PI}=$ propidium iodide. $n=4$; data presented as means \pm S.E.M. 


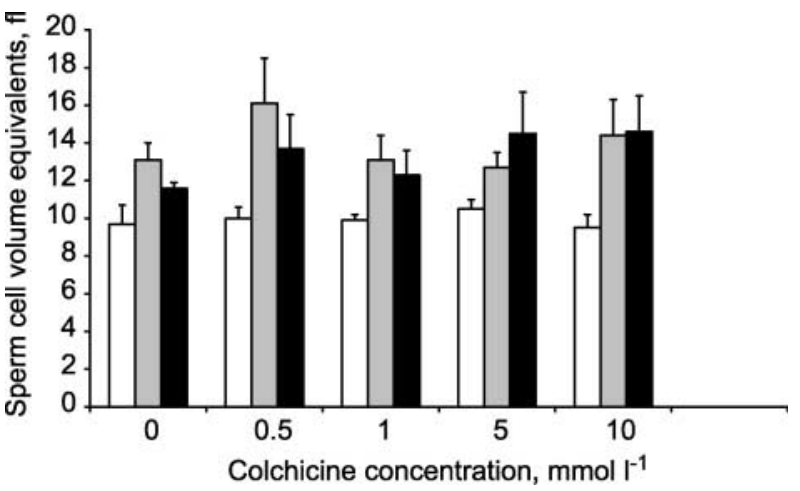

Figure 6 Sperm cell volume response to colchicine. White bars: isotonic cell volume; grey bars: hypotonic cell volume after $5 \mathrm{~min}$ of exposure to hypotonic conditions; black bars: hypotonic cell volume after $15 \mathrm{~min}$ of exposure to hypotonic conditions. Concentrations from 0.5 to $10 \mathrm{mmol} / \mathrm{l}$ were tested. Control sperm showed RVD, colchicine-treated sperm showed no RVD at concentrations where viability was affected $(>0.5 \mathrm{mmol} / \mathrm{l}) . n=4$; data presented as means \pm S.E.M.

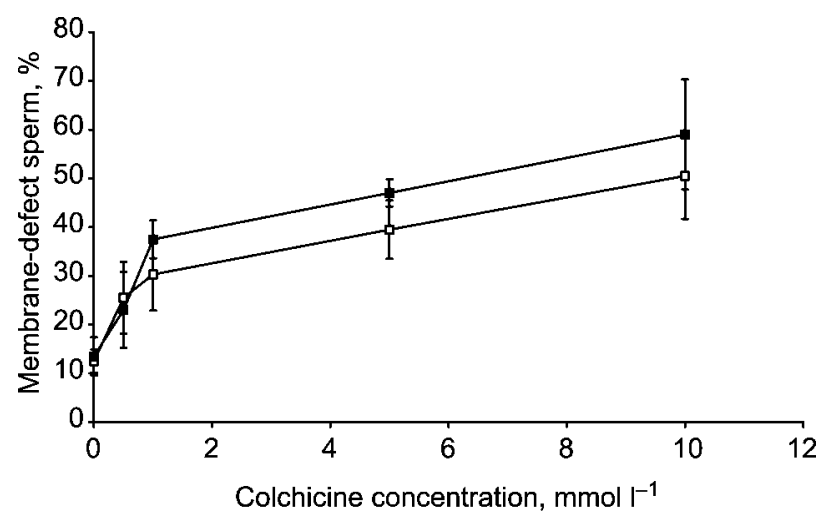

Figure 7 Sperm viability in the presence of colchicine. $\square$, proportion of PI-positive sperm under isotonic conditions; - proportion of PIpositive sperm under hypotonic conditions. At concentration $>0.5 \mathrm{mmol} / \mathrm{l}$ the cell death is significantly increased under both osmotic conditions as compared with controls, and progressed thereafter in a linear manner with the concentration $(P<0.05)$.

$\mathrm{PI}=$ propidium iodide. $n=4$; data presented as means \pm S.E.M.

RVD was not influenced) was no significant difference found between control and treated sperm suspensions with respect to the percentage of membrane-defect cells.

The isotonic volume of freshly diluted, Percoll-washed boar spermatozoa was not significantly affected by treatment with $500 \mu \mathrm{mol} / \mathrm{l}$ colchicine.

\section{Effect of colchicine on volume response and membrane integrity of capacitated boar spermatozoa}

Unlike washed sperm, hypotonic volumes of colchicinetreated sperm were not increased compared with controls, either at the beginning or at the end of incubation under capacitating conditions (Fig. 8). No RVD was observed at the tested concentration. No significant differences between control and treated suspension were observed with respect to $V_{\mathrm{r}}$, although the values in the colchicinetreated suspension were somewhat lower than controls $(17 \%)$ after $5 \mathrm{~min}$ of exposure to hypotonic conditions at the beginning of incubation. No differences with respect to membrane integrity were observed at the beginning of incubation. In contrast, at the end of incubation, the percentage of membrane-defect cells after addition of colchicine to a hypotonic solution was significantly higher than in controls (76 vs $58.8 \%, P<0.05$ ), and noticeable after addition to sperm incubated in isotonic solution (56.3 vs $44 \%, P<0.08$ ).

\section{Cytoskeletal requirements for capacitation-induced changes in volume response, membrane integrity, acrosomal state and motility}

In this series, incubation-induced parameter changes in sperm incubated in Tyrode medium in the presence of colchicine were compared with those of sperm incubated without additives to test whether the modification of the cytoskeletal sperm organization during capacitation may account for associated changes in sperm cell volume such as complete loss of RVD in non-treated capacitated sperm.

Incubation in the presence of colchicine resulted in an increase of the isotonic volume and decreased relative swelling after $5 \mathrm{~min}$ ( $V_{\text {iso }}=10.6$ vs $9.1 \mathrm{fl}$ in controls, $P<0.05 ; \quad V_{\text {hypo }} / V_{\text {iso }}=1.47$ vs 1.71 in controls, a tendency which had already been observed at the beginning of incubation; Fig. 4). No other noticeable effects on $V_{r}$ were observed. No effects on total motility, and track velocities VSL, VAP and VCL in the population of motile cells were observed between cells capacitated in the presence of colchicine and without it (data not shown). Although addition of colchicine resulted in a considerably higher proportion of membrane-defect cells $(P<0.05)$ during incubation in capacitating medium, the rates of cell death were almost identical in both treatments (Fig. 9). Both at the beginning and at the end of incubation the rate of spontaneous acrosome reaction was higher in the presence of colchicine ( 8.8 vs $5 \%$ at the beginning and 10.8 vs $7 \%$ at the end of incubation), while the rate of induced acrosome reaction was lower (10.5 vs $14.8 \%$ at the beginning and 22 vs $23.8 \%$ at the end of incubation), although it was not statistically significant.

\section{Discussion}

This study revealed that volume response and regulatory ability of native and capacitated sperm are affected by cytochalasin D and colchicine in different ways. Cytochalasin D induced a markedly lower initial volume response to hypotonic conditions and inhibited the following RVD, while colchicine increased the swelling level and did not affect RVD in native (but not in capacitated) sperm. One of the reasons behind these phenomena may be cytoskeletal involvement in the activation of mechanisms responsible for volume regulation such as activation or 


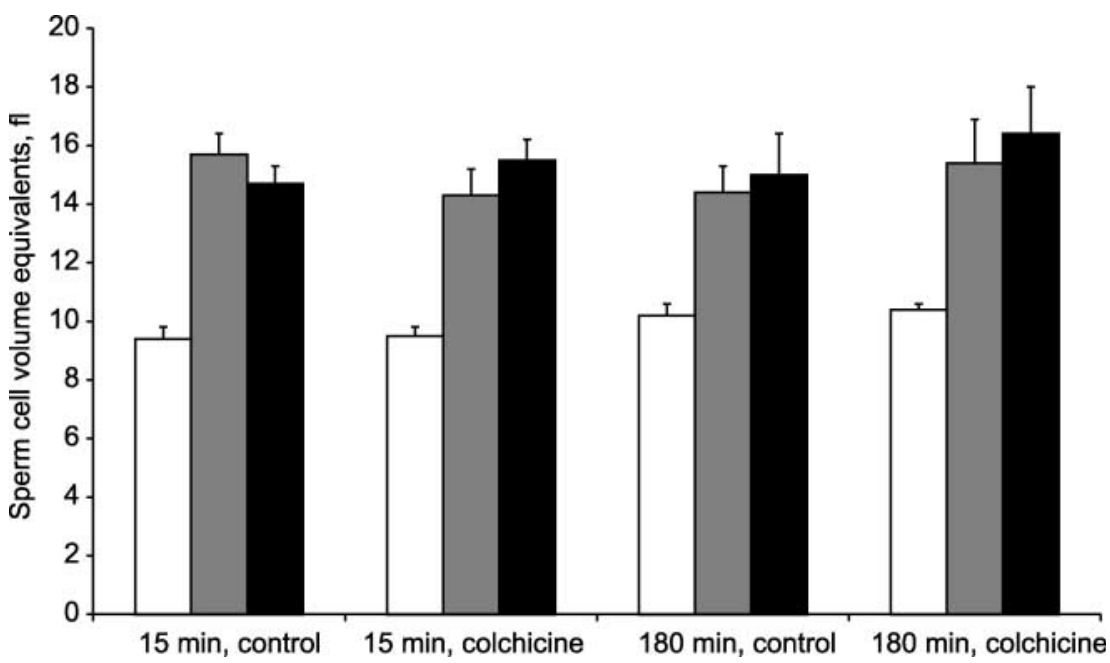

Figure 8 Cell volume response to colchicine at the beginning and at the end of capacitation treatment. White bars: isotonic cell volume; grey bars: hypotonic cell volume after 5 min of exposure to hypotonic conditions; black bars: hypotonic cell volume after 20 min of exposure to hypotonic conditions. Volumetric measurements were made on sperm incubated in the presence of colchicine in the incubation and testing solutions and control sperm after 10 and $180 \mathrm{~min}$ of incubation. A concentration of $0.5 \mathrm{mmol} / \mathrm{l}$ was tested. Colchicine-treated sperm volumes were not significantly different from the controls, unlike for Percoll-washed sperm. No RVD was observed in colchicine-treated sperm at both the beginning and end of the incubation period. $n=4$; data presented as means \pm S.E.M.

deactivation of ionic conductances. Cytochalasin D could activate $\mathrm{Cl}^{-}$currents in a concentration-dependent way. In human cervical cancer cells, cytochalasin B, an actindepolymerizing compound, induced a substantial increase in $\mathrm{Cl}^{-}$conductance under isotonic condition and potentiated the expression of $\mathrm{Cl}^{-}$currents in hypotonic stress

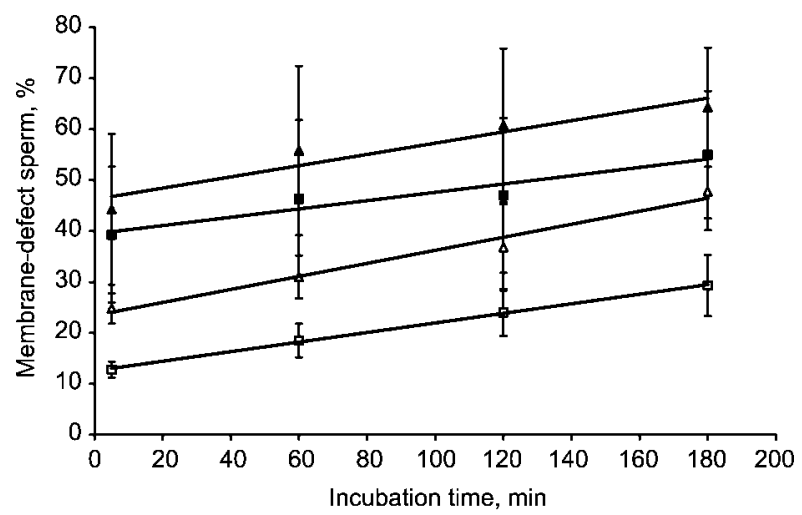

Figure 9 Sperm viability during incubation under capacitating conditions in the presence and absence of colchicine. $\square$, the percentage of membrane-defect sperm in control suspensions assessed under isotonic conditions; $\Delta$, the percentage of membrane-defect sperm in control suspensions assessed under hypotonic conditions; $\mathbf{\square}$, the percentage of membrane-defect sperm in suspensions incubated with colchicine assessed under isotonic conditions; $\boldsymbol{\Delta}$ the percentage of membrane-defect sperm in suspensions incubated with colchicine assessed under hypotonic conditions. Both under iso- and hypotonic conditions the cell death is markedly elevated $(P<0.05)$ but progressed at the same rate. Colchicine, isotonic conditions: $\mathrm{PI}=0.08 \mathrm{t}+39.46 ; R^{2}=0.92 ;$ controls, isotonic conditions: $\mathrm{PI}=0.09 t+12.58 ; R^{2}=0.99 ;$ colchicine, hypotonic conditions: $\mathrm{PI}=0.11 \mathrm{t}+46.22 ; R^{2}=0.91 ;$ controls, hypotonic conditions: $\mathrm{PI}=0.13 \mathrm{t}+23.41 ; R^{2}=0.98 . \mathrm{PI}=$ propidium iodide. $n=4$; data presented as means \pm S.E.M.
(Shen et al. 1999). Ahmed et al. (2000) demonstrated experimental evidence for activation of ClC-2 channels, belonging to the chloride channel forming protein family, by cytochalasin D. Such activation could accelerate and facilitate volume adjustment within a shorter time, as seen after $5 \mathrm{~min}$ of incubation for native sperm. On the other hand, disruption of microfilaments or microtubules produced by cytochalasin $\mathrm{D}$ or colchicine could disrupt the basis for the long-term sperm volume regulation so an elevated swelling level after a longer incubation might be observed. In heart muscle cells it was demonstrated that the plasma membrane was in close contact with actin, spectrin and desmin filaments (Larsen et al. 2000). These filaments remained during the hypotonic challenge structurally intact, indicating their positive role for stabilizing the cell response. The increasing cell volumes after 20 min of hypotonic incubation allow one to conclude that intact microfilaments are required for maintaining an appropriate swelling level and volume regulation. At higher concentrations the negative effect on the microfilament network appears to be stronger than the possible facilitating effects on $\mathrm{Cl}^{-}$conductivity. That depolymerization of the cytoskeletal filamentous actin by cytochalasin $\mathrm{D}$ leads to enhanced swelling had already been noted for mouse sperm, which previously had been reported to show resistance to swelling, probably due to anchoring of the plasma membrane through cytoskeletal interaction (Noiles et al. 1995, 1997). The varying effect of cytochala$\sin \mathrm{D}$ is therefore possibly due to addressing different mechanisms responsible for volumetric response at lower and higher concentrations.

Although the swelling level increased under addition of colchicine, the ability to regulate cell volume was maintained, indicating that microtubules disruption does 
not affect regulatory mechanisms to the extent that microfilament disruption does. It might be possible that colchicine treatment led to the changes in the osmotically active cell volume $38 \%$ for native boar sperm and boar sperm with short exposure to capacitating conditions (Gilmore et al. 1996, Petrunkina \& Töpfer-Petersen 2000)) so that a higher swelling level is possible.

The role of the F-actin cytoskeleton in cell volume regulation in various cell types has largely been investigated using cytochalasins to disrupt F-actin and highly varying effects have been reported. In Ehrlich ascites tumour cells (EATCs), cell swelling is associated with a decrease, and cell shrinkage with an increase in F-actin content respectively (Pedersen et al. 1999, 2001). The effect of cytochalasin treatment cannot, however, always be assumed to be F-actin depolymerization. At a concentration verified to depolymerize F-actin, cytochalasin B, but not cytochalasin $\mathrm{D}$, inhibited both the RVD and increase processes in EATCs, suggesting that the effect of cytochalasins may be related to an effect other than F-actin depolymerization (Pedersen et al. 1999). In the present study, cytochalasin effects on capacitating sperm at the beginning of incubation were largely comparable with those observed for Percoll-washed sperm. It is unlikely that the effect of cytochalasin $\mathrm{D}$ at this stage is related to depolymerization of F-actin; uncapacitated boar sperm did not show F-actin polymerization (Saxena et al. 1986), so the effect after a few minutes of incubation cannot be explained thereby. This indicates that the modulation of the cytoskeleton relevant to the sensitivity of volume regulation to cytochalasin D probably happens at later stages of capacitation. Apparently, very early changes in membrane architecture and protein kinase activity related to capacitation (Harrison et al. 1996, Gadella \& Harrison 2002, Harrison \& Miller 2000) are not linked to the ability to swell or to regulate the cell volume in response to cytochalasin D. During capacitation, a decrease in swelling level and disturbance of the regulatory volume function were observed. These findings conform with those reported previously (Petrounkina et al. 2000, Petrunkina \& TöpferPetersen 2000), where a decrease in relative volume swelling during incubation was observed for both ejaculated and epididymal sperm exposed to capacitating conditions. Interestingly, after $180 \mathrm{~min}$ of incubation, sperm lose ability to show a volumetric response to cytochalasin D under hypotonic conditions. A likely explanation could be that $\mathrm{Cl}^{-}$channels, apparently involved in boar sperm volume regulation (Petrunkina et al. 2001), may lose their functionality during capacitation. Such a phenomenon has already been observed for quinine-inhibitable $\mathrm{K}^{+}$channels, which became dysfunctional in capacitated bull sperm (Kulkarni et al. 1997). In this case, cytochalasin D would fail to activate these channels so no response would be seen. It must be noted that such inactivation is initiated probably not very rapidly - sperm incubated for a few minutes in capacitation medium still have diminished $V_{r}$ and fail to show significant RVD.
In contrast, the elevated swelling level and ability to regulate cell volume observed in Percoll-washed sperm under addition of colchicine were abolished in sperm after a short incubation under capacitating conditions. It is important that control values were somewhat higher than in Percoll-washed sperm so the changes in microtubule organization, i.e. increase in membrane permeability or osmotically active cell volume, which are sensitive to colchicine treatment may already occur within a short exposure to capacitating conditions. No further changes were observed after $3 \mathrm{~h}$, indicating that modification of volume regulatory mechanisms during long-term capacitation does not relate to changes in the microtubule network.

Since F-actin is developed in most regions of the boar sperm cell during the capacitation period (Saxena et al. 1986), it is possible that the appearance of microfilaments during capacitation in vitro is partly related to changes in cell volume. It should be emphasized that the ability to regulate cell volume to the levels close to the isotonic volume in suspensions incubated in the presence of cytochalasin $\mathrm{D}$ is not due to the higher cell death (as the rate of cell death was almost equal to that of the controls, it cannot account for different response at the end of incubation). Capacitation is interpreted as a positive destabilizing process (Harrison 1996). The loss or restriction of ability to show an appropriate cell volume in response to capacitating conditions observed in our previous studies (Petrunkina \& Töpfer-Petersen 2000, Petrounkina et al. 2000) can be a part of the destabilizing process. Previously, it was demonstrated that fertilization by boar sperm is reduced by treatment with cytochalasin D (Castellani-Ceresa et al. 1993). Similarly, for bull, ram, mouse and human sperm it was reported that inhibition of F-actin formation by cytochalasin D blocked sperm capacitation and reduced the in vitro fertilization rate (Brener et al. 2003). In this context, sperm incubated in the presence of cytochalasin D and which were showing partially improved volume regulation (about 20\%) probably failed to undergo some destabilizing steps, and, therefore, they would be unable to acquire the fertilizing ability. Surprisingly, no major effect on motility parameters and acrosome reaction was found by addition of either cytochalasin D or colchicine to capacitation medium, although recent studies confirmed participation of the cytoskeleton in the process of the acrosome reaction of mammalian spermatozoa (Palecek et al. 1999, Brener et al. 2003); however, a tendency to a reduction in the rates of induced acrosome reaction was observed. Addition of colchicine to capacitation medium resulted in a significant increase of the isotonic volume as compared with control medium. Apparently, cells incubated under capacitating conditions in the presence of colchicine are not able to regulate their volume under isotonic conditions, in contrast to non-capacitated sperm. An intact microtubule network was found to be crucial for the influence of cell volume on alkalinization of intracellular vesicles 
(Schreiber et al. 1994), so disruption of microtubules under capacitating conditions may probably result in several discrepancies between volume regulatory and other cellular functions such as controlling intracellular $\mathrm{pH}$ during capacitation. Apart from increased cell damage by colchicine within a very short initial time period, cell death progressed at equal rates during incubation. Thus, it appears unlikely that lower swelling levels after short exposure to hypotonic conditions are due to cell damage; rather it is a consequence of disturbed volume regulation under isotonic conditions.

Although the meaning of the cell volume changes recorded within the period of increasing membrane-defect cells noted in this study during incubation under capacitating conditions should be treated with some caution, it reflects the general destabilization processes associated with capacitation such as overall loss in osmotically induced volume responsiveness and RVD (Hebel et al. 2000, Petrunkina \& Töpfer-Petersen 2000, Petrounkina et al. 2000). Cell death caused by bicarbonate treatment, which is a feature of capacitation (Harrison 1996), follows primary, more subtle changes in cell volume. Nevertheless, the cell volume changes could be used as a measure of osmotically induced cell response during capacitation as only an osmotically active cell population was used in the calculations. Besides, the significant increase of membrane-defect cells was observed both under control incubation conditions and after addition of cytoskeleton modulators, which progressed at the same or similar rates as in controls. Thus, the kinetics of membrane damage appears not to be influenced by these effectors. Therefore, comparisons of volume changes measured within this incubation period between treated and non-treated suspensions are possible.

In conclusion, the results of this study demonstrate for the first time that the microfilament network appears to be important for volume regulation in boar spermatozoa. Intact microtubules do not seem to be necessary for osmotically induced volume regulation, although they influence the initial volume response of native sperm and isotonic cell volume during capacitation. The changes in cytoskeleton microfilament organization during capacitation affecting osmotically induced volume response appear to occur after longer incubation under capacitating conditions, suggesting that actin polymerization might represent a novel important regulatory pathway that is associated with modulation of volume regulatory function during completion of capacitation. In contrast, it seems that changes in microtubules, related to volume regulatory ability could be programmed within first stages of capacitation.

\section{Acknowledgements}

The financial support of the Deutsche Forschungsgemeinschaft (grant refs To114/6-1), the Dr Dr hc Karl-EiblFoundation (Neustadt ad Aisch) and Zentralverband der
Deutschen Schweineproduktion (ZDS e, Bonn) is gratefully acknowledged.

\section{References}

Ahmed N, Ramjeesingh M, Wong S, Varga A, Garami E \& Bear CE 2000 Chloride channel activity of ClC-2 is modified by the actin cytoskeleton. Biochemical Journal 352 789-794.

Al-Habori M 1994 Cell volume and ion transport regulation. International Journal of Biochemistry 26 319-334.

Brener E, Rubinstein S, Cohen G, Shternall K, Rivlin J \& Breitbart H 2003 Remodelling of the actin cytoskeleton during mammalian sperm capacitation and acrosome reaction. Biology of Reproduction 68 837-845.

Castellani-Ceresa L, Mattioli M, Radaelli G, Barboni B \& Brivio MF 1993 Actin polymerization in boar spermatozoa: fertilization is reduced with use of cytochalasin D. Molecular Reproduction and Development 36 203-211.

Cornet M, Lambert IH \& Hoffmann EK 1993 Relation between cytoskeleton, hypo-osmotic treatment and volume regulation in Ehrlich ascites tumor cells. Journal of Membrane Biology 131 55-66.

De Lamirande E, Leclerc P \& Gagnon C 1997 Capacitation as a regulatory event that primes spermatozoa for the acrosome reaction and fertilization. Molecular Human Reproduction 3 175-194.

Downey GP, Grinstein S, Sue-A-Quan A, Czaban B \& Chan CK 1995 Volume regulation in leukocytes: requirement for an intact cytoskeleton. Journal of Cell Physiology 163 96-104.

Drevius L-O 1972 Bull spermatozoa as osmometers. Journal of Reproduction and Fertility 28 29-39.

Gadella BM \& Harrison RAP 2002 Capacitation induces cyclic adenosine 3',5'-monophosphate-dependent, but apoptosis-unrelated, exposure of aminophospholipids at the apical head plasma membrane of boar sperm cells. Biology of Reproduction 67 340-350.

Gilmore JA, Du J, Tao J, Peter AT \& Critser JK 1996 Osmotic properties of boar spermatozoa and their relevance to cryopreservation. Journal of Reproduction and Fertility 107 87-95.

Grinstein S, Rothstein A, Sarkadi B \& Gelfand EW 1984 Responses of lymphocytes to anisotonic media: volume-regulating behaviour. American Journal of Physiology 246 C204-C215.

Harrison RAP 1996 Capacitation mechanisms, and the role of capacitation as seen in eutherian mammals. Reproduction, Fertility, and Development 8 591-594.

Harrison RAP \& Miller NGA 2000 cAMP-dependent protein kinase control of plasma membrane lipid architecture in boar sperm. Molecular Reproduction and Development 55 220-228.

Harrison RAP \& Vickers SE 1990 Use of fluorescent probes to access membrane integrity in mammalian spermatozoa. Journal of Reproduction and Fertility 88 343-352.

Harrison RAP, Mairet B \& Miller NGA 1993 Flow cytometric studies of bicarbonate-mediated $\mathrm{Ca}^{2+}$ influx in boar sperm populations. Molecular Reproduction and Development 35 197-208.

Harrison RAP, Ashworth PJ \& Miller NGA 1996 Bicarbonate/CO $\mathrm{CO}_{2}$, an effector of capacitation, induces a rapid and reversible change in the lipid architecture of boar sperm plasma membranes. Molecular Reproduction and Development 45 378-391.

Hebel M, Petrounkina AM, Weitze KF \& Töpfer-Petersen E 2000 Physiologically induced disturbance of regulative volume decrease in boar spermatozoa. Reproduction in Domestic Animals 3513 [Abstract].

Hoffmann EK \& Dunham PB 1995 Membrane mechanisms and intracellular signalling in cell volume recognition. International Reviews of Cytology 161 173-262.

Johnson LA, Aalbers JG \& Grooten HJG 1988 Artificial insemination of swine: fecundity of boar semen stored in Beltsville TS (BTS), Modified Modena (MM), or MR-A and inseminated on one, three and four days after collection. Zuchthygiene 23 49-55. 
Koch JP \& Korbmacher C 2000 Mechanism of shrinkage activation of nonselective cation channels in M-1 mouse cortical collecting duct cells. Journal of Membrane Biology 177 231-242.

Kulkarni SB, Sauna ZE, Somlata V \& Sitaramam V 1997 Volume regulation of spermatozoa by quinine-sensitive channels. Molecular Reproduction and Development 46 535-550.

Larsen TH, Dalen H, Boyle R, Souza MM \& Lieberman M 2000 Cytoskeletal involvement during hypo-osmotic swelling and volume regulation in cultured chick cardiac myocytes. Histochemical Cell Biology 113 479-488.

Noiles EE, Bailey JL \& Storey BT 1995 The temperature dependence in the hydraulic conductivity, Lp, of the mouse sperm plasma membrane shows a discontinuity between 4 and 0 degrees C. Cryobiology 32 220-238.

Noiles EE, Thompson KA \& Storey BT 1997 Water permeability, Lp, of the mouse sperm plasma membrane and its activation energy are strongly dependent on interaction of the plasma membrane with the sperm cytoskeleton. Cryobiology 35 79-92.

O'Neill WC 1999 Physiological significance of volume-regulatory transporters. American Journal of Physiology 276 C995-C1011.

Palecek J, Peknicova J \& Vitu M 1999 Changes in immunochemical localization of cytoskeletal proteins in human and boar spermatozoa before and after acrosome reaction. Folia Biologica 45 13-20.

Pedersen SF, Mills JW \& Hoffmann EK 1999 Role of the F-actin cytoskeleton in the RVD and RVI processes in Ehrlich ascites tumor cells. Experimental Cell Research 252 63-74.

Pedersen SF, Hoffmann EK \& Mills JW 2001 The cytoskeleton and cell volume regulation. Comparative Biochemistry and Physiology Part A: Molecular and Integrative Physiology 130 385-399.

Petrounkina AM, Harrison RAP, Petzoldt R, Weitze KF \& TöpferPetersen E 2000 Cyclical changes in sperm volume during in vitro incubation under capacitating conditions: a novel boar sperm characteristic. Journal of Reproduction and Fertility 118 283-293.

Petrunkina AM \& Töpfer-Petersen E 2000 Heterogeneous osmotic behaviour in boar sperm populations and its relevance for detection of plasma membrane changes. Reproduction, Fertility, and Development 12 297-305.

Petrunkina AM, Harrison RAP, Hebel M, Weitze KF \& TöpferPetersen E 2001 Role of quinine sensitive channels in boar and bull sperm volume regulation. Reproduction 122 327-336.
Petrunkina AM, Radcke S, Günzel-Apel A-R, Harrison RAP \& TöpferPetersen E 2004 Role of potassium channels, the sodium-potassium pump and the cytoskeleton in the control of dog sperm volume. Theriogenology 61 35-54.

Sarkadi B \& Parker JC 1991 Activation of ion transport pathways by changes in cell volume. Biochimica et Biophysica Acta $\mathbf{1 0 7 1}$ 407-427.

Saxena N, Peterson RN, Saxena NK \& Russell LD 1986 Microfilaments appear in boar spermatozoa during capacitation in vitro. Journal of Experimental Zoology 239 423-427.

Schreiber R, Stoll B, Lang F \& Häussinger D 1994 Effects of anisoosmolarity and hydroperoxides on intracellular $\mathrm{pH}$ in isolated rat hepatocytes as assessed by $\left(2^{\prime}, 7^{\prime}\right)$-bis(carboxyethyl)-5(6)-carboxyfluorescein and fluorescein isothiocyanate-dextran fluorescence. Biochemical Journal 303 113-120.

Shen MR, Chou CY, Hsu KF, Hsu KS \& Wu ML 1999 Modulation of volume-sensitive $\mathrm{Cl}^{-}$channels and cell volume by actin filaments and microtubules in human cervical cancer HT-3 cells. Acta. Physiologica Scandinavica $167215-225$.

Strange K, Emma F \& Jackson PS 1996 Cellular and molecular physiology of volume-sensitive anion channels. American Journal of Physiology 270 C711-C730.

Yanagimachi R 1994 Mammalian fertilization. In The Physiology of Reproduction, pp S189-S317. Eds E Knobil \& JD Neill. New York: Raven Press.

Yeung CH \& Cooper TG 2001 Effects of the ion-channel blocker quinine on human sperm volume, kinematics and mucus penetration, and the involvement of potassium channels. Molecular Human Reproduction 7 819-828.

Yeung CH, Sonnenberg-Riethmacher E \& Cooper TG 1999 Infertile spermatozoa of c-ros tyrosine kinase receptor knockout mice show flagellar angulation and maturational defects in cell volume regulatory mechanisms. Biology of Reproduction 61 1062-1069.

Received 25 April 2003

First decision 28 July 2003

Accepted 30 September 2003 